\title{
Laparoscopic metabolic surgery for the treatment of type 2 diabetes in Asia: a scoping review and evidence-based analysis
}

Zhiyong Dong ${ }^{1 \dagger}$, Sheikh Mohammed Shariful Islam² ${ }^{2 \dagger}$ Ashley M. Yu ${ }^{3}$, Rui Qu', Bingsheng Guan ${ }^{1}$, Junchang Zhang ${ }^{1}$, Zhao Hong ${ }^{4}$ and Cunchuang Wang ${ }^{1 *}$

\begin{abstract}
Background: Laparoscopic metabolic surgery has been previously shown to be an effective treatment for obese patients with type 2 diabetes (T2DM). The objective of this scoping review is to determine the impact of metabolic surgery for the treatment of type 2 diabetes in Asia and perform an evidence-based analysis.

Methods: We performed a literature search in PubMed for research on laparoscopic metabolic surgery for the treatment of T2DM in Asia region. We classified the included studies based on the Oxford Center for Evidence Based Medicine guidelines. And performed and evidence analysis.

Results: In total, 205 articles were identified. $62.9 \%$ of the studies were from East Asia. The evidence of 26 studies are level I, 59 are level II. Laparoscopic sleeve gastrectomy (LSG) was the most commonly reported surgical procedure (63.1\%) in Asia. The number of laparoscopic metabolic surgery for T2DM in Asian countries has increased rapidly over the last 8 years. We identified 16 studies which showed that laparoscopic metabolic surgery is an effective and safe treatment for T2DM in patients with a BMl of $>25 \mathrm{~kg} / \mathrm{m}^{2}$ to $<35 \mathrm{~kg} / \mathrm{m}^{2}$ in Asia.
\end{abstract}

Conclusions: Our results suggest that laparoscopic metabolic surgery might be an effective and safe treatment for T2DM patients with BMI $<35 \mathrm{~kg} / \mathrm{m}^{2}$, and that LSG is the most commonly performed surgical procedure for this in Asia.

Keywords: Metabolic surgery, Type 2 diabetes, Obesity, BMl $<35 \mathrm{~kg} / \mathrm{m}^{2}$, evidence-based analysis

\section{Background}

The prevalence of type 2 diabetes mellitus (T2DM) and obesity is increasing rapidly worldwide, especially in developing countries [1]. The International Diabetes Federation reportedin 2015 that there were 450 million diabetic patients globally [2]. 85-95\% of the patients had T2DM, and $75 \%$ were from low-income countries [2]. $\mathrm{Ng}$ et al. [3] evaluated that the total number of obese persons were 671 million all over the world. 13\% of

\footnotetext{
* Correspondence: twcc2015@163.com

'Zhiyong Dong and Sheikh Mohammed Shariful Islam contributed equally to this work.

'Department of Bariatric Surgery, the First Affiliated Hospital of Jinan University, No.613, Huangpu Avenue West, Guangzhou 510630, China Full list of author information is available at the end of the article
}

them resided in the United States and 15\% in China and India. Obesity is recognized as one of the major risk factor for diabetes, coronary heart diseases, stroke, sleep apnea and cancer [4-6]. It is well known that uncontrolled obesity can lead to significant health problems, decrease life expectancy, and influence quality of life. Obesity and co-morbid diabetes imposes a significant global burden to health systems, societies, families, and individuals affected $[7,8]$.

Medical therapy can be of limited value in the treatment of obese patients with T2DM [9-11]. Wittgrove et al. [12] performed the first five cases of laparoscopic gastric bypass surgery in 1993-1994 which showed promising results of weight loss. Since then, laparoscopy has become the main method of bariatric surgery. In 1995, Walter Porieset al. [13] found that bariatric surgery can significantly reduce weight.

(c) The Author(s). 2018 Open Access This article is distributed under the terms of the Creative Commons Attribution 4.0 International License (http://creativecommons.org/licenses/by/4.0/), which permits unrestricted use, distribution, and 
In this same study, $83 \%$ of T2DM patients, and $98 \%$ of patients with impaired glucose tolerance, experienced postoperative normalization of blood sugar, serum insulin, and glycosylated hemoglobin, following surgery, and a long-term stabilization of T2DM remission [13]. Evidence shows that bariatric surgery not only control a patient's weight, but can also improve obesity-related complications, including hypertension, hyperlipidemia, snoring, sleep apnea syndrome, polycystic ovarian syndrome, and other metabolic diseases, especially T2DM [14-18]. At present, the common metabolic surgical procedures performed are: laparoscopic sleeve gastrectomy (LSG), laparoscopic adjustable gastric banding surgery (LAGB), laparoscopic biliopancreatic diversion with duodenal switch (BPD-DS), and laparoscopic Roux-en-Y gastric bypass (LRYGB) [19-21]. The most effective metabolic surgical procedures are the RYGB and duodenal switch [19-21].

Several reports of laparoscopic metabolic surgery for T2DM are available in different Asian countries. However, information regarding which surgical methods are most suitable for T2DM in Asia is scarce. Therefore, we performed this scoping review and evidence-based analysis to understand the current and common bariatric surgical procedures for T2DM in Asia.

\section{Methods}

\section{Search strategy}

We conducted a literature search from the electronic databases of PubMed from 1st January, 1994 to 19st November, 2017. The following key search terms were used: "bariatric surgery OR metabolic surgery OR obesity surgery OR weight loss surgery" AND "diabetes mellitus" AND "names of Asian countries and regions: according to WHO list of countries and regions." There were no language restrictions.

\section{Screening}

Three authors were involved in the independent title and abstract screening of potentially relevant articles. All screening was performed independently and in duplicate. If there were any discrepancies between authors and a consensus was unable to be reached, a fourth author was consulted.

\section{Inclusion and exclusion criteria}

Studies describing laparoscopic metabolic surgery for T2DM, in patients with or without obesity were included. Studies were included if they were conducted in one of 49 Asian countries. We excluded all studies from non-Asian countries, patients without type 2 diabetes, and any non-laparoscopic surgeries.

\section{Literature screening and data extraction}

Three reviewers (DZ, QR, GB) independently extracted the following terms from each study: year of publication, the country of first author, regions (East Asia, Southeast Asia, South Asia, West Asia, Central Asia), title, presence of patients with or without T2DM, language, type of bariatric surgery, and the type of clinical research (animal trials, basic research). All data was extracted in duplicate, and any disagreements of data extractionwere resolved through discussion between authors.

\section{Evidence grade criteria and statistical analysis}

Three reviewers (DZ, QR, GB) independently classified the clinical study, using Oxford Center for Evidence Based Medicine (EBM) Levels of Evidence guidelines (https:// www.cebm.net/2017/05/ocebm-levels-of-evidence/) [22]. Any difference between the reviewers was resolved by discussion. Data extraction was performed using Microsoft Excel 2007 software.

\section{Results}

\section{Literature search}

Our search yielded 919 articles (including 102 systematic review/meta-analyses, 52 randomized controlled trials (RCTs), 398 cohort studies, 129 case series, 238 case reports and others) from all over the world, and 205 articles in Asian countries (including 13 systematic review/ meta-analyses, 10 RCTs, 59 cohort studies, 35 case series, and 88 case report and others). Of the 205 reports included, 157 were clinical research, 44 were basic research, and four animal trials. Our study flow diagram is shown in Fig. 1.

\section{Laparoscopic metabolic surgery for T2DM in Asia}

From our search, there is a trend of increased reporting of literature on laparoscopic metabolic surgery for T2DM in Asian countries and regions over the past decade, as shown in Fig. 2.

\section{The distribution of reports on laparoscopic metabolic surgery for T2DM in Asia}

The distribution and proportion studies were: 129 papers from East Asia (62.9\%), mostly from China, Japan, and South Korea; 12 papers from Southeast Asia (5.9\%), located in Singapore, and Malaysia; 29 papers from South Asia (14.1\%), distributed in India; and 34 papers from West Asia (16.5\%), representing Israel, Turkey, and Saudi Arabia. Only one paper represented Central Asia (0.5\%) from Kazakhstan. These results are presented in Fig. 3.

\section{The level of clinical study on laparoscopic metabolic surgery for T2DM in Asia}

Clinical studies were classified according to the Oxford Center for EBM Levels of Evidence guidelines: Level I 1a 


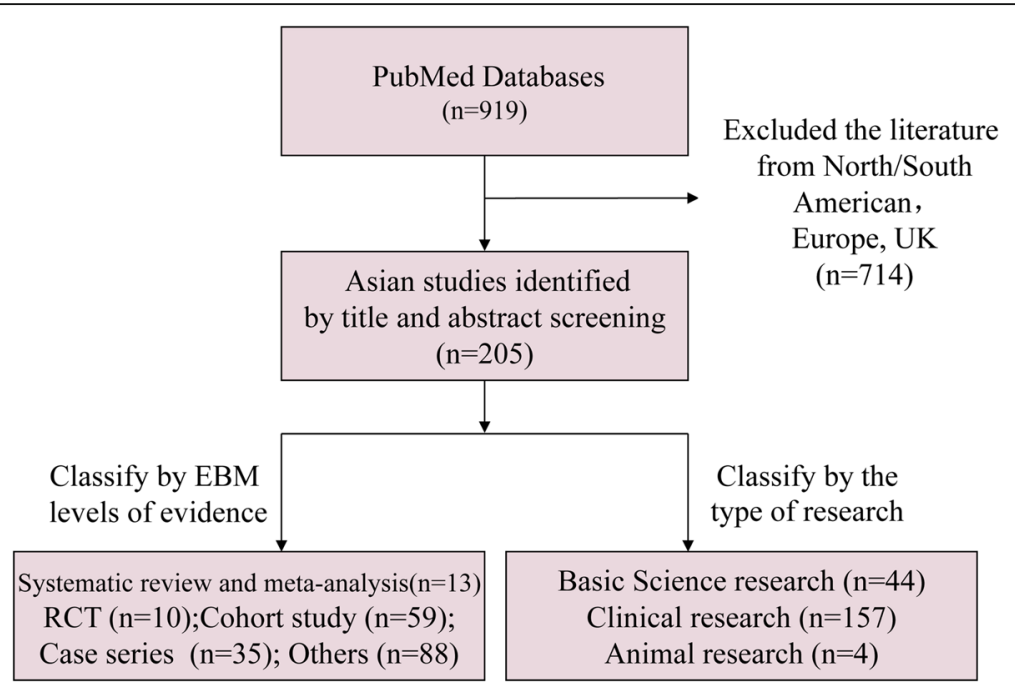

Fig. 1 Flow diagram of the search process and study classification

(systematic review/ meta-analysis) - 13 articles were published in Asia out of 102 globally, accounting for 12.7\%; Level I 1b (RCT) - 10 out of 52 globally (19.2\%); Level II 2b (cohort study) - 59 out of 398 globally (14.8\%); Level IV 4 (case series) - 35 out of 129 globally (27.1\%). Of the 238 case reports or other articles published globally representing Level V 5 evidence, 88 were from Asia (37.0\%) (Table 1).

The procedures of clinical study on laparoscopic metabolic surgery for T2DM in Asia

A total of 13,742 patients were reported to have undergone laparoscopic metabolic surgery for T2DM from the included studies in Asia. 3752 (27.3\%) cases were performed by LRYGB, and majority in East Asia (53.2\%). $8242(60.0 \%)$ cases by LSG, 70.4\% in East Asia. 653 (4.8\%) by LGAB, and $1095(8.0 \%)$ by other metabolic surgery procedures.

Clinical study of laparoscopic metabolic surgery for T2DM with $\mathrm{BMI}$ of $>25 \mathrm{~kg} / \mathrm{m}^{2}$ to $<35 \mathrm{~kg} / \mathrm{m}^{2}$ in Asia

There were two RCTs, one cohort study, and 14 case series whereby a total of 507 cases were performed by LRYGB, 172 by MGB, 107 by LSAGB, 57 by LJISSA and 51 by LSG. 16 studies were on laparoscopic metabolic surgery for T2DM with BMI of $>25 \mathrm{~kg} / \mathrm{m}^{2}$ to $<35 \mathrm{~kg} / \mathrm{m}^{2}$ in Asia (Table 2) [22-37]. Thirteen studies were from China, two from India, and one from South Korea. All the

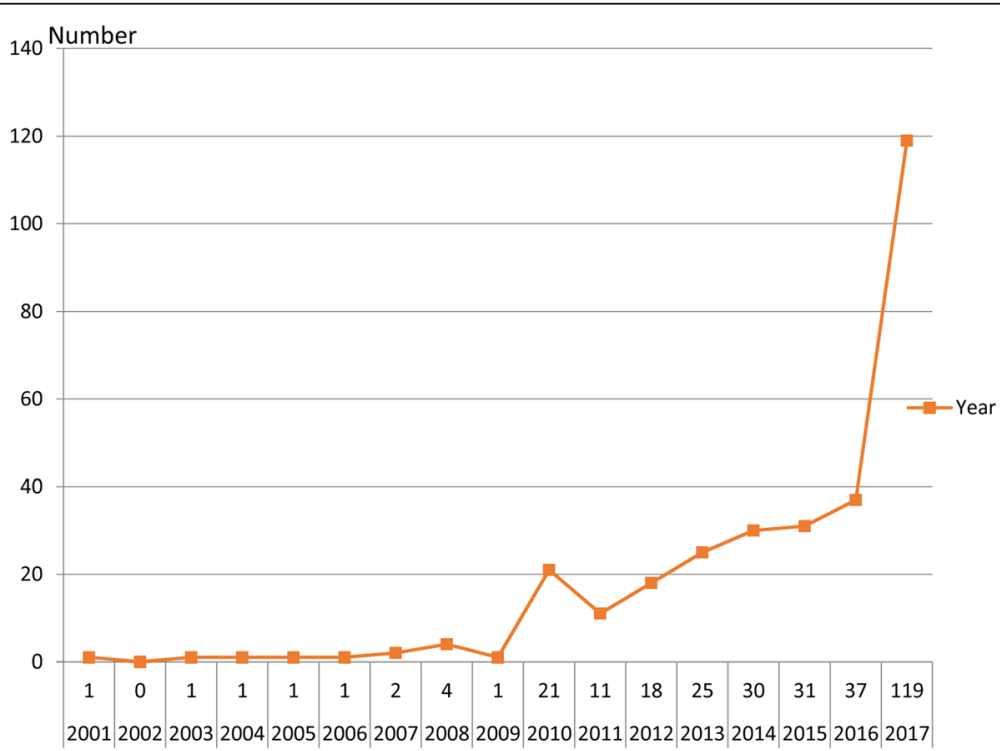

Fig. 2 The trends and numbers of literature on laparoscopic metabolic surgery for T2DM in Asia 


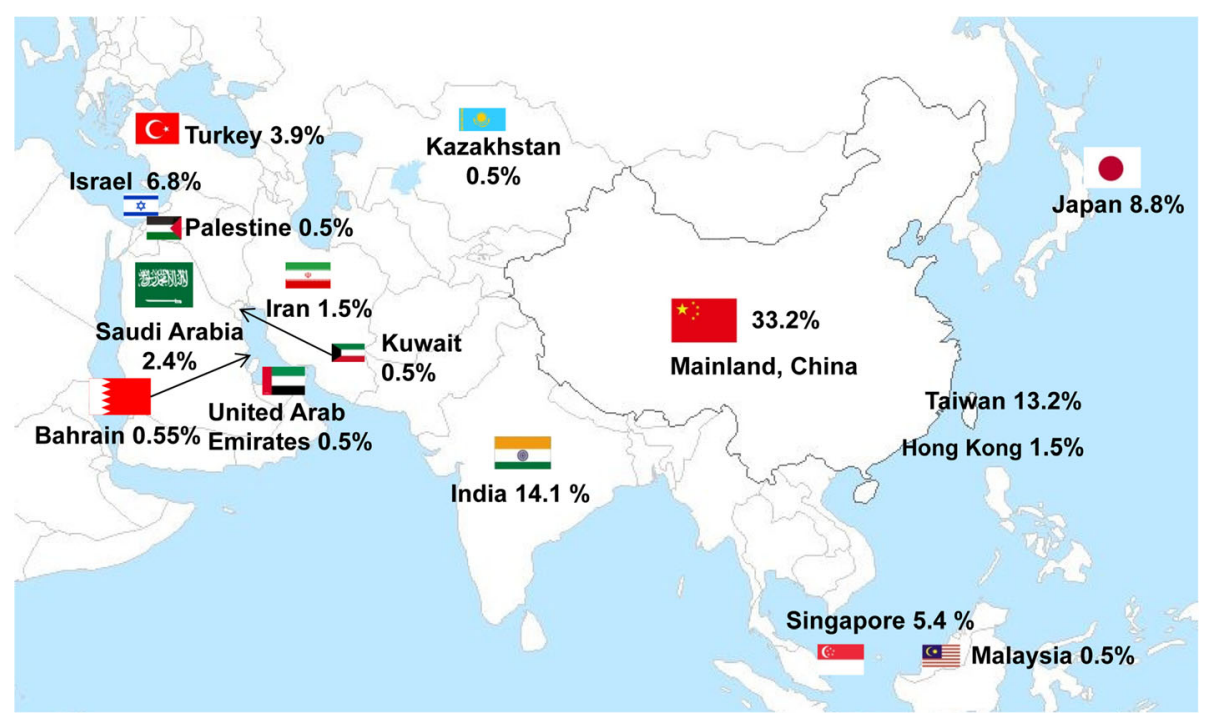

Fig. 3 The distribution and rate of literature on laparoscopic metabolic surgery for T2DM in country of Asia. (The initial map courtesy of "map.ps123.net")

16 studies reported a different rate, ranging from 53 to $96.2 \%$ of remission of diabetes in patients with T2DM and BMI of $>25 \mathrm{~kg} / \mathrm{m}^{2}$ to $<35 \mathrm{~kg} / \mathrm{m}^{2}$. There were no reported mortalities in any of the trials, post-operative follow-up times ranging from 1 week up to 5 years (Table 3). Moreover, the major complications were incomplete intestinal obstruction, mild upper gastrointestinal bleeding, excessive postoperative suture line bleeding with shock, anastomotic ulceration, anemia, low albumin, bile reflux, excess weight loss, early hemorrhage, marginal ulcers, seromas, nausea, vomitingand diarrhea, gastric fistula and infection, all complications were cured by symptomatic treatment (Table 3). These results suggest that laparoscopic metabolic surgery may be effectively used to treat T2DM in patients with BMI of $>25 \mathrm{~kg} / \mathrm{m}^{2}$ to $<35 \mathrm{~kg} / \mathrm{m}^{2}$ in Asia [23-38].

\section{Discussion}

This scoping review identified 205 studies of laparoscopic metabolic surgery for T2DM in Asia and performed an evidence-based analysis. Most of the studies were clinical research (78.0\%) and published in English (94.1\%) with increasing numbers of publication each year during the past decade. Using the Oxford Center for
EBM Levels of Evidence, only $12.1 \%$ of the studies were of Level I evidence, mostly conducted in East Asia (62.1\%). LSG was the most commonly reported surgical procedure, accounting for $64.9 \%$ in Asian countries. All studies reported that laparoscopic metabolic surgery was safe and effective for T2DM with or without obesity. There were 16 studies on T2DM with BMI of $>25 \mathrm{~kg} / \mathrm{m}^{2}$ to $<35 \mathrm{~kg} / \mathrm{m}^{2}$, mostly from China. $70.2 \%$ procedures were LRYGB [23-38]. Our review suggests that laparoscopic metabolic surgery might be a safe and effective treatment in T2DM patients with BMI from $25 \mathrm{~kg} / \mathrm{m}^{2}$ to $35 \mathrm{~kg} / \mathrm{m}^{2}$.

This study suggests that the use of laparoscopic metabolic surgery for T2DM is increasing in Asia, especially in China and India. This may be due to the increasing number of obese patients in this region. Adela Hruby et al. [39] reported that from 1980 to 2010, in most Asian countries and region, the incidence of obesity and overweight has increased in both children and adults. Obesity is highly prevalent in China and India, representing a high proportion of the total number of people with obesity and diabetes globally [40]. The role of laparoscopic metabolic surgery for obesity with T2DM has been included in many national guidelines in Asia and

Table 1 The level of included clinical study on laparoscopic metabolic surgery for T2DM

\begin{tabular}{lllll}
\hline Levels & Type of study & No. of World & No. of Asian & Rates \\
\hline I $1 \mathrm{a}$ & Systematic review/ meta-analysis & 102 & 13 & $12.7 \%(13 / 102)$ \\
I 1b & RCT & 52 & 10 & $19.2 \%(10 / 52)$ \\
II $2 \mathrm{~b}$ & Cohort study & 398 & 59 & $14.8 \%(59 / 398)$ \\
IV 4 & Case series & 129 & 35 & $27.1 \%(35 / 129)$ \\
V 5 & Case report/other & 238 & 88 & $37.0 \%(88 / 238)$ \\
\hline
\end{tabular}




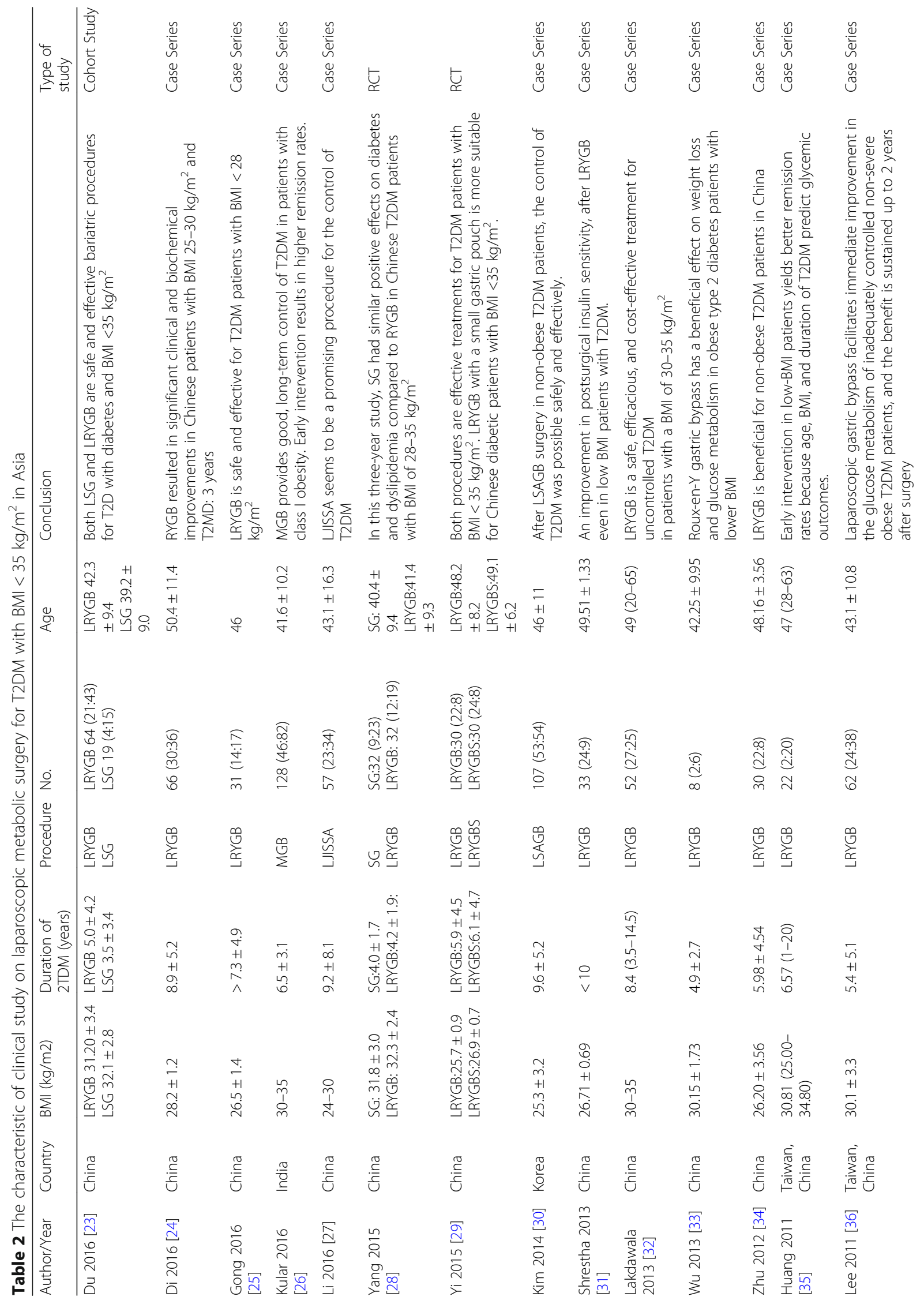




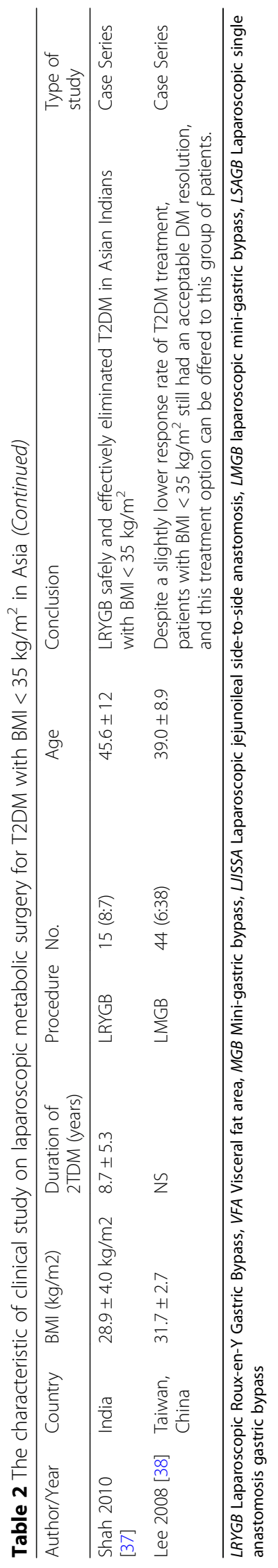




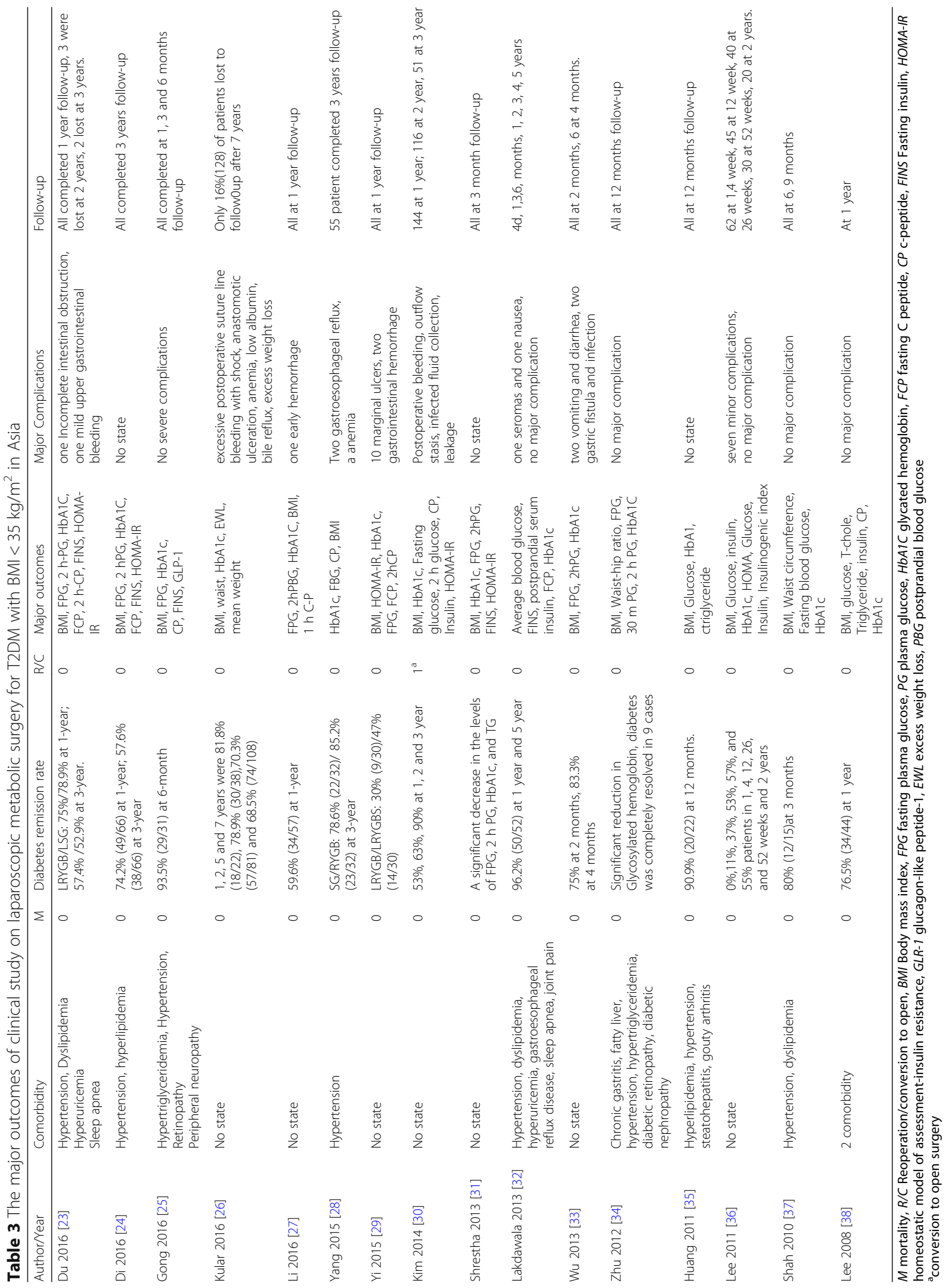


other regions globally [41-43]. The recent increases in funding investments in medical research in China could also be a contributing factor to the increase in the number of studies. The total number of international publication in China has ranked second in the world in 2015, which may indicate that there is more scientific activities being conducted in China [44]. It is reported that there were 50 million bariatric surgeries globally in 2014, LSG accounting for $51.7 \%$, RYGB $26.8 \%$, BPD-DS $11.5 \%$, and AGB 9.5\% [45]. The 3rd annual conference of Chinese Society for Metabolic and Bariatric Surgery in 2015 reported that in China, LSG accounted for $65.5 \%$ and LRYGB 28.9\% of bariatric procedures.

Previous studies have shown that LSG is a low-risk, easy to perform, faster, less expensive, and more effective weight loss procedure with lower complication rates, and may have a better safety profile in the short-term compared to LRYGB [46-48]. However, Li JF et al. [49] suggested that LRYGB is more effective than LSG for the treatment of T2DM and metabolic syndrome. Yang et al. [27] reported in a RCT of 64 patients that both LSG with LRYGB procedures achieved complete remission of T2DM with glycated hemoglobin (HbA1c) $<6.0 \%$ without taking any diabetic medications. The LRYGB group had significantly greater weight loss than the SG group $(p=0.017)$. A cohort study among 304 patients indicated that LRYGB showed improved effectiveness in T2DM resolution when compared to LSG at a 5-year follow-up assessment [50]. Evidence also suggests that LRYGB could rapidly improve insulin resistance and associated pancreatic beta-cell function [51, 52]. And both LSG and LRYGB have been suggested as safe and effective bariatric procedures for obesity [53]. Therefore, laparoscopic metabolic surgery has been widely recommended as the most effective treatment for T2DM patients with $\mathrm{BMI} \geq 35 \mathrm{~kg} / \mathrm{m}^{2}$ or in patients with one or more severe obesity-related co-morbidities (T2DM, hypertension, hyperlipidemia, obstructive sleep apnea, etc.) [54-57]. Laparoscopic metabolic surgery also be considered to be an option to treat T2MD in patients with BMI $30.0-34.9 \mathrm{~kg} / \mathrm{m}^{2}$ or $27.5-32.4 \mathrm{~kg} / \mathrm{m}^{2}$ in Asian descent, and inadequately controlled hyperglycemia despite optimal medical treatment by either oral or injectable insulin during Diabetes Surgery Summit II [54].

This investigation reveals interesting results that the research of laparoscopic metabolic surgery for T2DM with BMI of $>25 \mathrm{~kg} / \mathrm{m}^{2}$ to $<35 \mathrm{~kg} / \mathrm{m}^{2}$ has increased in Asian countries (Fig. 2; Table 3), and all studies had an acceptable diabetes mellitus resolution (remission rate range from 52.9 to $96.2 \%$ at 1,3 , or 5 years). A meta-analysis including nine trials (from China, USA, Chile, Brazil and Spain) with T2DM and BMI $<35 \mathrm{~kg} /$ $\mathrm{m}^{2}$ undergoing LRYGB, suggested that these patients had a significant decrease in BMI $(P<0.00001)$, remission of diabetes (glucose, $P<0.00001$, hemoglobin A1c, $P<0.00001)$ at 12 months follow-up [58]. Lee et al. [38] investigated 201 patients with impaired fasting glucose or T2DM undergoing laparoscopic mini-gastric bypass, and showed that $76.5 \%$ patients with $25 \mathrm{~kg} / \mathrm{m}^{2}<$ BMI $<35 \mathrm{~kg} / \mathrm{m}^{2}$ met treatment goals $(\mathrm{HbA1C}<7 \%$, LDL $<150 \mathrm{mg} / \mathrm{dl}$, triglyceride $<150 \mathrm{mg} / \mathrm{dl}$ ) compared with $92.4 \%$ patients with $\mathrm{BMI}>35 \mathrm{~kg} / \mathrm{m}^{2}$. Although, all 16 studies in our review showed that laparoscopic metabolic surgery is effective for patients with BMI of > $25 \mathrm{~kg} / \mathrm{m}^{2}$ to $<35 \mathrm{~kg} / \mathrm{m}^{2}$ in Asian countries, further research is needed to determine whether these effects are universal across other countries. Moreover, there were no mortalities nor severe complications reported in any of trials (Table 3) [23-38]. And the Table 3 showed that most surgery for T2DM with low BMI were performed in East Asia, which is correlated with a lower BMI than in European/western patients, the risk of T2DM in different ethnics is different. In Asia, the related complication of T2DM occurred when BMI is not high. This might also influences indication for "diabetes-surgery" [18, 59-61].

This review has some limitations: Firstly, this study only analyzed the Asian literature from a single database, PubMed, and might not include studies published in other regional or national databases. Secondly, we could not perform a meta-analysis in our present study to compare the differences between low and high (BMI $>25 \mathrm{~kg} / \mathrm{m}^{2}$ to $<35 \mathrm{~kg} / \mathrm{m}^{2}$ vs BMI $\geq 35 \mathrm{~kg} / \mathrm{m}^{2}$ ) and other characteristics due to heterogeneity of the reports. Thirdly, there is a lack of well-designed rigorous randomized controlled trials investigating this intervention, and therefore a paucity of high-level evidence to support any recommendations. Therefore, further research is obligatory to understand long-term health outcomes, improvements and sustainability of the glycemic control and advance surgical procedures.

\section{Conclusions}

This review demonstrated that SLG and LRYGBP are the two commonly used surgical procedures for T2DM patients with comorbid obesity in Asia. Laparoscopic metabolic surgery can be performed in T2DM patients with BMI of $>25 \mathrm{~kg} / \mathrm{m}^{2}$ to $<35 \mathrm{~kg} / \mathrm{m}^{2}$. However, there is a need for further research to identify long-term complications, sustained rates of diabetes resolution, and promotion of the further development of metabolic surgery in Asia.

\section{Abbreviations}

BMI: Body Mass Index; BPD-DS: Laparoscopic biliopancreatic diversion with duodenal switch; EBM: Evidence-based medicine; IDF: International Diabetes Federation; LAGB: Laparoscopic adjustable gastric banding surgery; 
LRYGB: Laparoscopic Roux-en-Y gastric bypass; LSG: Laparoscopic sleeve gastrectomy; RCT: Randomized control trial; T2DM: Type 2 diabetes

\section{Availability of data and materials}

Not applicable to this study as no datasets were generated during the current study. We used data from published papers.

\section{Authors' contributions}

$\mathrm{CW}, \mathrm{ZH}$ and $\mathrm{ZD}$ designed the study. ZD, AY and SI drafted the manuscript. $\mathrm{ZD}, \mathrm{SI}, \mathrm{QR}, \mathrm{BG}$ and JZ extracted the data and analysis the selected papers. All authors reviewed and approved the final version of this paper.

\section{Author's information}

Our author team has expertise in Evidence-based medicine, epidemiology, and meta-analysis. CW, ZD, QR, BG and Jz are surgeons in laparoscopic metabolic surgery for T2DM.

\section{Ethics approval and consent to participate}

Not applicable.

\section{Consent for publication}

Not applicable.

\section{Competing interests}

All authors declare that they have no competing interests.

\section{Publisher's note}

Springer Nature remains neutral with regard to jurisdictional claims in published maps and institutional affiliations.

\section{Author details}

${ }^{1}$ Department of Bariatric Surgery, the First Affiliated Hospital of Jinan University, No.613, Huangpu Avenue West, Guangzhou 510630, China. ${ }^{2}$ Institute for Physical Activity and Nutrition (IPAN), Deakin University, Melbourne, VIC 3125, Australia. ${ }^{3}$ Faculty of Medicine, University of Ottawa, Ottawa, Canada. ${ }^{4}$ Robert H Lurie Medical Research Center, Feinberg School of Medicine, Northwestern University, Chicago, IL 60611, USA.

\section{Received: 25 May 2018 Accepted: 6 September 2018}

\section{Published online: 17 September 2018}

\section{References}

1. Islam SM, Purnat TD, Phuong NT, Mwingira U, Schacht K, Fröschl G. Noncommunicable diseases (NCDs) in developing countries: a symposium report. Global Health. 2014;10:81.

2. International Diabetes Federation (IDF). IDF Diabetes Atlas. 8th Edition. Brussels: International Diabetes Federation; 2017. http://www.diabetesatlas.org. Accessed 19 Nov 2017

3. Ng M, Fleming T, Robinson $M$, et al. Global, regional, and national prevalence of overweight and obesity in children and adults during 19802013: a systematic analysis for the global burden of disease study 2013. Lancet. 2014;384(9945):766-81.

4. Lavie CJ, Milani RV, Ventura HO. Obesity and cardiovascular disease: risk factor, paradox, and impact of weight loss. J Am Coll Cardiol. 2009;53(21): 1925-32.

5. Koh-Banerjee $P$, Wang Y, Hu FB, Spiegelman D, Willett WC, Rimm EB. Changes in body weight and body fat distribution as risk factors for clinical diabetes in US men. Am J Epidemiol. 2004;159(12):1150-9.

6. Dobbins M, Decorby K, Choi BC. The association between obesity and cancer risk: a meta-analysis of observational studies from 1985 to 2011. ISRN Prev Med. 2013;2013:680536.

7. Chan RS, Woo J. Prevention of overweight and obesity: how effective is the current public health approach. Int J Environ Res Public Health. 2010;7(3): 765-83.

8. Islam SMS, Lechner A, Ferrari U, et al. Healthcare use and expenditure for diabetes in Bangladesh. BMJ Global Health. 2017;2(1):e000033.

9. Mingrone G, Panunzi S, De Gaetano A, et al. Bariatric-metabolic surgery versus conventional medical treatment in obese patients with type 2 diabetes: 5 year follow-up of an open-label, single-Centre, randomised controlled trial. Lancet. 2015;386(9997):964-73.
10. Mingrone G, Panunzi S, De Gaetano A, et al. Bariatric surgery versus conventional medical therapy for type 2 diabetes. N Engl J Med. 2012; 366(17):1577-85.

11. Yan $Y$, Sha $Y$, Yao $G$, et al. Roux-en-Y gastric bypass versus medical treatment for type 2 diabetes mellitus in obese patients: a systematic review and meta-analysis of randomized controlled trials. Medicine (Baltimore). 2016;95(17):e3462.

12. Wittgrove AC, Clark GW, Tremblay LJ. Laparoscopic gastric bypass, roux-enY: preliminary report of five cases. Obes Surg. 1994;4(4):353-7.

13. Pories WJ, Swanson MS, MacDonald KG, et al. Who would have thought it? An operation proves to be the most effective therapy for adult-onset diabetes mellitus. Ann Surg. 1995;222(3):339-50 discussion 50-2.

14. Kalyvas AV, Hughes M, Koutsarnakis C, et al. Efficacy, complications and cost of surgical interventions for idiopathic intracranial hypertension: a systematic review of the literature. Acta Neurochir. 2017;159(1):33-49.

15. Skubleny D, Switzer NJ, Gill RS, et al. The impact of bariatric surgery on polycystic ovary syndrome: a systematic review and meta-analysis. Obes Surg. 2016;26(1):169-76.

16. Nagendran M, Carlin AM, Bacal D, et al. Self-reported remission of obstructive sleep apnea following bariatric surgery: cohort study. Surg Obes Relat Dis. 2015:11(3):697-703.

17. Wu GZ, Cai B, Yu F, et al. Meta-analysis of bariatric surgery versus nonsurgical treatment for type 2 diabetes mellitus. Oncotarget. 2016;7(52): 87511-22.

18. Cummings DE, Cohen RV. Bariatric/metabolic surgery to treat type 2 diabetes in patients with a BMl $<35 \mathrm{~kg} / \mathrm{m}^{2}$. Diabetes Care. 2016;39(6):924-33.

19. Kumar N. Weight loss endoscopy: development, applications, and current status. World J Gastroenterol. 2016;22(31):7069-79.

20. Umemura A, Lee WJ, Sasaki A, Wakabayashi G. History and current status of bariatric and metabolic surgeries in East Asia. Asian J Endosc Surg. 2015;8(3): 268-74.

21. American Society For Metabolic \& Bariatric Surgery (ASMBS). Bariatric Surgical Society Takes On New Name, New Mission And New Surgery. https://www.medicalnewstoday.com/releases/80433.php.

22. Phillips BBC, Sackett D, Badenoch D, Straus S, Haynes B, Dawes M. Updated by Jeremy Howick March 2009. Oxford Centre for Evidencebased Medicine - Levels of Evidence (March 2009). 1998. Available from https://www.cebm.net/2009/06/oxford-centre-evidence-based-medicinelevels-evidence-march-2009/.

23. Du X, Zhou HX, Zhang SQ, Tian HM, Zhou ZG, Cheng Z. A comparative study of the metabolic effects of LSG and LRYGB in Chinese diabetes patients with $\mathrm{BMI}<35 \mathrm{~kg} / \mathrm{m}^{2}$. Surg Obes Relat Dis. 2017;13(2):189-97.

24. Di J, Zhang $H$, Yu H, Zhang $P$, Wang Z, Jia W. Effect of roux-en-Y gastric bypass on the remission of type 2 diabetes: a 3-year study in Chinese patients with a BMl $<30 \mathrm{~kg} / \mathrm{m}^{2}$. Surg Obes Relat Dis. 2016;12(7):1357-63.

25. Gong K, Li K, Zhang N, et al. Gastric bypass procedure for type 2 diabetes patients with BMl $<28$ kg/m². Surg Endosc. 2017;31(3):1172-9.

26. Kular KS, Manchanda N, Cheema GK. Seven years of mini-gastric bypass in type II diabetes patients with a body mass index $<35 \mathrm{~kg} / \mathrm{m}(2)$. Obes Surg. 2016;26(7):1457-62.

27. Li J, Xie G, Tian Q, Hu Y, Meng Q, Zhang M. Laparoscopic jejunoileal side-toside anastomosis for the treatment of type 2 diabetes mellitus in Chinese patients with a body mass index of $24-32 \mathrm{~kg} / \mathrm{m}^{2}$. J Cancer Res Ther. 2016; 12(Supplement):5-10.

28. Yang J, Wang C, Cao G, et al. Long-term effects of laparoscopic sleeve gastrectomy versus roux-en-Y gastric bypass for the treatment of Chinese type 2 diabetes mellitus patients with body mass index $28-35 \mathrm{~kg} / \mathrm{m}(2)$. BMC Surg. 2015;15:88.

29. Yi B, Jiang J, Zhu L, Li P, Im I, Zhu S. Comparison of the effects of roux-en-Y gastrojejunostomy and LRYGB with small stomach pouch on type 2 diabetes mellitus in patients with BMl $<35 \mathrm{~kg} / \mathrm{m}(2)$. Surg Obes Relat Dis. 2015:11(5):1061-8.

30. Kim MJ, Hur KY. Short-term outcomes of laparoscopic single anastomosis gastric bypass (LSAGB) for the treatment of type 2 diabetes in lower BMI (< $30 \mathrm{~kg} / \mathrm{m}(2))$ patients. Obes Surg. 2014;24(7):1044-51.

31. Shrestha C, He H, Liu Y, Zhu S, Xiong J, Mo Z. Changes in Adipokines following laparoscopic rouX-en-Y gastric bypass surgery in Chinese individuals with type 2 diabetes mellitus and BMl of 22-30 kg.M(-2). Int. J Endocrinol. 2013;2013:240971.

32. Lakdawala M, Shaikh S, Bandukwala S, Remedios C, Shah M, Bhasker AG. Roux-en-Y gastric bypass stands the test of time: 5 -year results in low body 
mass index (30-35 kg/m(2)) Indian patients with type 2 diabetes mellitus. Surg Obes Relat Dis. 2013;9(3):370-8.

33. Wu Q, Xiao Z, Cheng Z, Tian H. Changes of blood glucose and gastrointestinal hormones 4 months after roux-en-Y gastric bypass surgery in Chinese obese type 2 diabetes patients with lower body mass index. J Diabetes Investig. 2013;4(2):214-21.

34. Zhu L, Mo Z, Yang $X$, et al. Effect of laparoscopic roux-en-Y gastroenterostomy with BMl<35 kg/m(2) in type 2 diabetes mellitus. Obes Surg. 2012;22(10):1562-7.

35. Huang CK, Shabbir A, Lo CH, Tai CM, Chen YS, Houng JY. Laparoscopic roux-en-Y gastric bypass for the treatment of type II diabetes mellitus in Chinese patients with body mass index of 25-35. Obes Surg. 2011;21(9): 1344-9.

36. Lee WJ, Chong K, Chen CY, et al. Diabetes remission and insulin secretion after gastric bypass in patients with body mass index $<35 \mathrm{~kg} / \mathrm{m}^{2}$. Obes Surg. 2011;21(7):889-95.

37. Shah SS, Todkar JS, Shah PS, Cummings DE. Diabetes remission and reduced cardiovascular risk after gastric bypass in Asian Indians with body mass index < $35 \mathrm{~kg} / \mathrm{m}(2)$. Surg Obes Relat Dis. 2010;6(4):332-8.

38. Lee WJ, Wang W, Lee YC, et al. Effect of laparoscopic mini-gastric bypass for type 2 diabetes mellitus: comparison of $\mathrm{BMI}>35$ and $<35 \mathrm{~kg} / \mathrm{m}^{2}$. J Gastrointest Surg. 2008;12(5):945-52.

39. Hruby A, Hu FB. The epidemiology of obesity: a big picture. Pharmacoeconomics. 2015;33(7):673-89.

40. Collaboration NCDRF. Trends in adult body-mass index in 200 countries from 1975 to 2014: a pooled analysis of 1698 population-based measurement studies with 19.2 million participants. Lancet. 2016; 387(10026):1377-96.

41. Kim MK, Lee WY, Kang JH, et al. 2014 clinical practice guidelines for overweight and obesity in Korea. Endocrinol Metab (Seoul). 2014;29(4): 405-9.

42. Lee WJ, Aung L. Metabolic surgery for type 2 diabetes mellitus: experience from Asia. Diabetes Metab J. 2016;40(6):433-43.

43. (NGC). NGC. Guideline summary: Clinical practice guidelines for the management of overweight and obesity in adults, adolescents and children in Australia. In: National Guideline Clearinghouse (NGC) Website] Rockville (MD): Agency for Healthcare Research and Quality (AHRQ); 2013. Available: https://www.guideline.gov. Accessed 19 Nov 2017.

44. XM H. SJTU Ranks Second in 2014 Total Cites of International Publication in China. http://en.sjtu.edu.cn/news/sjtu-ranks-second-in-2014-total-cites-ofinternational-publication-in-china/ 2014; (Accessed 19 Nov 2017).

45. American Society for Metabolic and Bariatric Surgery (ASMBS) ObesityWeek 2015. Based on the best estimation from available data. http://2015. obesityweek.com/welcome-to-obesityweek-2015/.

46. El Chaar M, Hammoud N, Ezeji G, Claros L, Miletics M, Stoltzfus J. Laparoscopic sleeve gastrectomy versus laparoscopic roux-en-Y gastric bypass: a single center experience with 2 years follow-up. Obes Surg. 2015; 25(2):254-62.

47. Biter LU, van Buuren MMA, Mannaerts GHH, et al. Quality of life 1 year after laparoscopic sleeve gastrectomy versus laparoscopic roux-en-Y gastric bypass: a randomized controlled trial focusing on gastroesophageal reflux disease. Obes Surg. 2017;27(10):2557-65.

48. Arabi Basharic F, OlyaeeManesh A, Ranjbar Ezzat Abadi M, Shiryazdi SM, Shabahang $H$, Jangjoo A. Evaluation of laparoscopic sleeve gastrectomy compared with laparoscopic Roux-en-Y gastric bypass for people with morbid obesity: A systematic review and meta-analysis. Med I Islam Repub Iran. 2016:3:354

49. Li JF, Lai DD, Ni B, Sun KX. Comparison of laparoscopic roux-en-Y gastric bypass with laparoscopic sleeve gastrectomy for morbid obesity or type 2 diabetes mellitus: a meta-analysis of randomized controlled trials. Can J Surg. 2013;56(6):E158-64

50. Perrone F, Bianciardi E, Ippoliti S, Nardella J, Fabi F, Gentileschi P. Long-term effects of laparoscopic sleeve gastrectomy versus roux-en-Y gastric bypass for the treatment of morbid obesity: a monocentric prospective study with minimum follow-up of 5 years. Updat Surg. 2017;69(1):101-7.

51. Solomon TP, Haus JM, Kelly KR, Rocco M, Kashyap SR, Kirwan JP. Improved pancreatic beta-cell function in type 2 diabetic patients after lifestyleinduced weight loss is related to glucose-dependent insulinotropic polypeptide. Diabetes Care. 2010;33(7):1561-6.

52. Tinahones FJ, Queipo-Ortuno MI, Clemente-Postigo M, Fernnadez-Garcia D, Mingrone G, Cardona F. Postprandial hypertriglyceridemia predicts improvement in insulin resistance in obese patients after bariatric surgery. Surg Obes Relat Dis. 2013;9(2):213-8.

53. Li J, Lai D, Wu D. Laparoscopic roux-en-Y gastric bypass versus laparoscopic sleeve gastrectomy to treat morbid obesity-related comorbidities: a systematic review and meta-analysis. Obes Surg. 2016;26(2):429-42.

54. Rubino F, Nathan DM, Eckel RH, et al. Metabolic surgery in the treatment algorithm for type 2 diabetes: a joint statement by international diabetes organizations. Diabetes Care. 2016;39(6):861-77.

55. Mechanick Jl, Youdim A, Jones DB, et al. Clinical practice guidelines for the perioperative nutritional, metabolic, and nonsurgical support of the bariatric surgery patient-2013 update: cosponsored by American Association of Clinical Endocrinologists, the Obesity Society, and American Society for Metabolic \& bariatric surgery. Surg Obes Relat Dis. 2013;9(2):159-91.

56. Garber AJ, Abrahamson MJ, Barzilay Jl, et al. Consensus statement by the American Association of Clinical Endocrinologists and American College of endocrinology on the comprehensive type 2 diabetes management Algorithm-2017 executive summary. Endocr Pract. 2017;23(2):207-38.

57. Stegenga $H$, Haines $A$, Jones $K$, et al. GUIDELINES identification, assessment, and management of overweight and obesity: summary of updated NICE guidance. Bmj-Brit Med J. 2014;349.

58. Rao WS, Shan CX, Zhang W, Jiang DZ, Qiu M. A meta-analysis of short-term outcomes of patients with type 2 diabetes mellitus and BMI $\leq 35 \mathrm{~kg} / \mathrm{m}(2)$ undergoing roux-en-Y gastric bypass. World J Surg. 2015;39(1):223-30.

59. Yip WCY, Sequeira IR, Plank LD, Poppitt SD. Prevalence of Pre-Diabetes across Ethnicities: A Review of Impaired Fasting Glucose (IFG) and Impaired Glucose Tolerance (IGT) for Classification of Dysglycaemia. Nutrients. 2017; 9(11)

60. Ma RC, Chan JC. Type 2 diabetes in east Asians: similarities and differences with populations in Europe and the United States. Ann N Y Acad Sci. 2013; 1281:64-91.

61. Boffetta P, McLerran D, Chen Y, et al. Body mass index and diabetes in Asia: a cross-sectional pooled analysis of 900,000 individuals in the Asia cohort consortium. PLoS One. 2011:6(6):e19930.

\section{Ready to submit your research? Choose BMC and benefit from:}

- fast, convenient online submission

- thorough peer review by experienced researchers in your field

- rapid publication on acceptance

- support for research data, including large and complex data types

- gold Open Access which fosters wider collaboration and increased citations

- maximum visibility for your research: over $100 \mathrm{M}$ website views per year

At $\mathrm{BMC}$, research is always in progress.

Learn more biomedcentral.com/submissions 